\title{
The Effects of Porcelain Polishing Techniques on the Color and Surface Texture of Different Porcelain Systems*
}

\author{
Ali Riza Tuncdemir ${ }^{1 \#}$, Erhan Dilber ${ }^{2}$, Haluk Baris Kara ${ }^{3}$, A. Nilgun Ozturk ${ }^{2}$ \\ ${ }^{1}$ Department of Prosthodontics, Mustafa Kemal University, Antakya, Turkey; ${ }^{2}$ Department of Prosthodontics, Faculty of Dentistry, \\ Selçuk University, Konya, Turkey; ${ }^{3}$ Department of Prosthodontics, Medipol University, Istanbul, Turkey. \\ Email: "lirizatuncdemir@gmail.com
}

Received March $8^{\text {th }}, 2012$; revised April $2^{\text {nd }}, 2012$; accepted May $4^{\text {th }}, 2012$

\begin{abstract}
The aim of this study was to compare the effects of different porcelain polishing techniques on the color change and surface roughness of feldspathic porcelains and lithium disilicate glass-ceramic system. 80 porcelain specimens were divided into two subgroups, each subgroup was divided into 4 groups of 10 specimens. Surfaces were polished with different ceramic polishers. VITA Easyshade spectrophotometer was used to measure color differences. Surface roughness was evaluated using a profilometer. The color change and surface roughness of porcelains were statistically analyzed by Two-way ANOVA followed by a Tukey HSD test $(\alpha=05)$. There were relationships between the porcelain systems and polishing techniques $(\mathrm{p}<0.01)$ but no significant differences between porcelain systems for surface $\mathrm{Ra}$ values $(\mathrm{p}>0.05)$. For $\Delta \mathrm{E}$ values, there was relationship between the porcelain systems and polishing techniques $(\mathrm{p}<$ $0.01)$ but no significant differences between porcelain systems $(p>0.05)$. Chairside porcelain polishing systems were not able to provide a porcelain surface as smooth as the glazed surface for the IPS empress and Ceramco 3 porcelains.
\end{abstract}

Keywords: Color; Glaze; Polish; Porcelain; Surface Roughness

\section{Introduction}

The clinical use of porcelain materials has increased extensively due to its advantages biocompatibility, durability and desirable esthetic properties [1]. It also has simplified bonding procedures [2]. The final surface of porcelain finish is achieved by glazing. Dentists sometimes remove glazed surface after cementation because of occlusal adjustment, contour correction or esthetic improvement [3]. If the porcelain surface is roughened by this procedure, it may facilitate bacterial plaque accumulation leading to carries and periodontal diseases. Therefore roughness porcelain surfaces should be subjected to finishing and polishing procedures. Additionally, the color of porcelain restoration is affected by surface roughness because a rough surface reflects light irregularly and less than a glazed surface [4].

On account of the complex optical characteristics of tooth color, achieving an excellent esthetic is a difficult process. Successful esthetic restorations require the integration of several critical factors, such as the color matching ability of the dentist and the light source used for color evaluation as well as the surface and structural

"This study was presented in the 45th Meeting of the Continental European Division of the International Association for Dental Research (CED-IADR) with the Scandinavian Division.

\#Corresponding author. characteristics of the tooth and restorative materials [5]. To be successful, clinicians require the understanding of color, light and related characteristics of porcelain and resin.

The CIE L ${ }^{*} \mathrm{a}^{*} \mathrm{~b}^{*}$ system is scientifically based and used for calculating color differences. $\Delta \mathrm{L}^{*}, \Delta \mathrm{a}^{*}, \Delta \mathrm{b}^{*}$ are the differences in the CIE color-space parameters of the two colors [6]. $\Delta \mathrm{E}$ values are used to describe whether the changes in the overall shade are perceivable to the people. If the magnitude of color difference is less than 1 unit $(\Delta \mathrm{E}<1)$ a color match between two colors judged, between 1 to $2 \Delta \mathrm{E}$ unit range frequently true judgements are made by the people. Greater than $2 \Delta \mathrm{E}$ units, all observers can apparently detect color differences between 2 colors. 3.7 $\Delta \mathrm{E}$ unit is clinically acceptable limit of the color differences value [7]. Obviously, the optical characteristics of tooth color are complex.

Polishing can reduce chairtime, eliminates laboratory procedures, infection control may be obtained as studies supporting to use of polishing techniques instead of glazing and may also have the advantage of reducing the wear of the opposing dentition [8,9]. Polishing is important for the porcelain surface for function and esthetic so several different techniques have been described for repolishing porcelain surfaces in the mouth [10]. Several 
authors have described different polishing techniques as an alternative using for glazing [11-13].

On the other hand, glazed ceramic surfaces may increase the fracture resistance of the ceramic [1]. According to other studies mechanical polishing was not able to improve surface roughness in comparison to the original glaze surfaces [14-17].

Theese conflicting results are the differences of experimental designs, dental ceramics and polishing methods or combination of ceramic and polishing technique.

The aim of this in vitro study was to compare the effects of different porcelain polishing techniques and glazing on the color change $(\Delta \mathrm{E})$ and surface roughness (Ra) of a feldspathic (Ceramco 3) and lithium disilicate glass - ceramic system (IPS empress II). It also sought to examine the effect of polishing techniques on the surface texture of the porcelains qualitatively using scanning electron microscopy.

The research hypothesis was that the different porcelain polishing tecniques would have the similar effects with glazed specimens on the color change and surface roughness of porcelains.

\section{Materials and Methods}

Specimens were fabricated using a metal mold $12 \mathrm{~mm}$ in diameter and $1 \mathrm{~mm}$ thick. Low fusing feldspathic porcelain (Ceramco 3, Dentsply, Burlington, USA) and lithium disilicate glass-ceramic systems (IPS Empress II, Ivoclar Vivadent, Schaan, Liechtenstein) were used for this study.

For low-fusing feldspathic porcelain, each specimen was mixed using the same amount of porcelain and, liquid before being placed into the mold. The excess moisture was absorbed by using a tissue (Selpak, Eczacibasi Holding, Istanbul, Turkey). After removal from the mold, the specimens were placed in a porcelain-firing oven (Multimat ${ }^{\circledR} \mathrm{C}$, Dentsply, USA) and fired at $650^{\circ} \mathrm{C}$. The temrature was increased by $50^{\circ} \mathrm{C} / \mathrm{min}$. After reaching $930^{\circ} \mathrm{C}$, the specimens were held at this temperature for 1 minute according to the manufacturer's instruction. Then the overglaze (Ceramco 2 low temp glaze, Dentsply) was applied to the specimens. After application of the overglaze, the specimens were placed again into the porcelain-firing oven at a starting temperature of $600^{\circ} \mathrm{C}$. After reaching $910^{\circ} \mathrm{C}$, the specimens were held at this temperature for 1 minute. The porcelain discs were $10 \mathrm{~mm}$ in diameter and $1 \mathrm{~mm}$ thick due to shrinking.

Lithium disilicate glass-ceramic systems (IPS Empress 2 ingot shade No. 100, Ivoclar Vivadent, Schaan, Liechtenstein) were fabricated using the lost-wax technique. Specimens were waxed to their proper shape $(10 \mathrm{~mm}$ in diameter and $1 \mathrm{~mm}$ thick) using metal mold. It was then invested into a special flask with a special type of phos- phate-bonded investment material (IPS PressVest Speed, Ivoclar-Vivadent). The desired shade of a ceramic ingot was plastified at $920^{\circ} \mathrm{C}$ and pressed under a vacuum into the investment's mold. The press furnace Programat EP600 (Ivoclar-Vivadent) was used (Heat pressing conditions were as follows: stand-by temperature $700^{\circ} \mathrm{C}$; temperature increase $60^{\circ} \mathrm{C} / \mathrm{min}$; press temperature $920^{\circ} \mathrm{C}$; holding time $25 \mathrm{~min}$ ). Then the overglaze (E. max Ceram Glaze Paste, Ivoclar Vivadent) was applied to the specimens according to the manufacturer's instructions. After application of the overglaze, the specimens were placed into the porcelain firing oven (Heat pressing conditions were as follows: stand-by temperature $403^{\circ} \mathrm{C}$; temperature increase $55^{\circ} \mathrm{C} / \mathrm{min}$; temperature $780^{\circ} \mathrm{C}$; holding time $30 \mathrm{sec})$.

The 80 specimens were divided into 8 groups of 10 specimens ( 4 groups for the feldspathic and 4 groups for the lithium disilicate glass-ceramic specimens) One group served as the control (F: Feldspathic ceramic, E: Lithium disilicate glass-ceramic, FC: Feldspathic ceramic control group, EC: Lithium disilicate glass-ceramic control group) and had no surface treatment. In the experimental groups (K: Diamond Ceramic Polisher set, S: Occlusal Brush set, M: Ceramic Polisher set, EK, ES, EM; FK, FS, FM) the glaze layer of each specimen was removed using a medium-grit diamond rotary cutting instrument (M\&A Diatek, The Netherlands) with water cooling to simulate clinical procedures. Then the surfaces were polished with 3 different ceramic polishers (codes: $\mathrm{K}, \mathrm{S}, \mathrm{M}$ ) which are shown in Table 1 . They were polished at $5000 \mathrm{rpm}$ without polishing paste and without water cooling for 20 seconds per the manufacturer's instructions. Polishing was performed by the same investigator. The specimens were then ultrasonically cleaned (Biosonic JR, Whaledent, New Jersey, USA) with distilled water and dried with a blast of air for 30 seconds before the color measurements.

Clinical spectrophotometer which comprises a base unit and a hand piece (VITA Zahnfabrik, Bad Säckingen, Germany) was used to measure color differences in the specimens according to the CIE $\mathrm{L}^{*} \mathrm{a}^{*} \mathrm{~b}^{*}$ color system. These measurements were made for each specimen, and the mean CIE L ${ }^{*}{ }^{*} b^{*}$ values were calculated. Colour differences of the samples were calculated using the following formulas:

Table 1. Materials used in this study.

\begin{tabular}{|c|c|c|c|}
\hline Product & Code & Lot no. & Manufacturer \\
\hline $\begin{array}{c}\text { Diamond } \\
\text { Ceramic Polisher }\end{array}$ & $\mathrm{K}$ & 3106143 & $\begin{array}{c}\text { Kerr, Bioggio, } \\
\text { Switzerland }\end{array}$ \\
\hline Occlusal Brush Set & $\mathrm{S}$ & 0120 & Stoddard, UK \\
\hline Ceramic Polisher & M & 14369 & $\begin{array}{c}\text { Meisinger, } \\
\text { Germany }\end{array}$ \\
\hline
\end{tabular}




$$
\begin{gathered}
\Delta \mathrm{E}=\left[\left(\Delta \mathrm{L}^{*}\right)^{2}+\left(\Delta \mathrm{a}^{*}\right)^{2}+\left(\Delta \mathrm{b}^{*}\right)^{2}\right]^{1 / 2} \\
\Delta \mathrm{E}=\left[\left(\mathrm{L}_{1}^{*}-\mathrm{L}_{2}^{*}\right)^{2}\right]+\left[\left(\mathrm{a}_{1}^{*}-\mathrm{a}_{2}^{*}\right)^{2}\right]+\left[\left(\mathrm{b}_{1}^{*}-\mathrm{b}_{2}^{*}\right)^{2}\right]^{1 / 2}
\end{gathered}
$$

The spectrophotometer was calibrated according to the manufacturer's instructions. All the measurements were performed keeping the tip of the spectrophotometer perpendicular to the discs and in contact with the discs surface. The quantitative $\Delta \mathrm{E}$ values between the control group and experimental groups were calculated with the following formula $[18,19]$.

$$
\Delta \mathrm{E}=\left[\left(\mathrm{L}_{\mathrm{E}}^{*}-\mathrm{L}_{\mathrm{C}}^{*}\right)^{2}+\left(\mathrm{a}_{\mathrm{E}}^{*}-\mathrm{a}_{\mathrm{C}}^{*}\right)^{2}+\left(\mathrm{b}_{\mathrm{E}}^{*}-\mathrm{b}_{\mathrm{C}}^{*}\right)^{2}\right]^{1 / 2}
$$

Surface roughness of the porcelain discs were evaluated using a profilometer (Mitotoyo Surf Test SJ 201 P/M; Mitutoyo Corp, Takatsu-ku, Japan). To measure the roughness value in $\mu \mathrm{m}$, the diamond stylus $(5-\mu \mathrm{m}$ tip radius) was moved across the surface under a constant load of $0.75 \mathrm{mN}$ with, a speed of $0.5 \mathrm{~mm} / \mathrm{s}$ and a range of $350 \mu \mathrm{m}$. The instrument was calibrated using a standart precision reference specimen. This procedure was repeated 3 times at a different location for each specimen to obtain the general surface characteristics of the specimens. The average values of these measurements were considered to be the Ra values. The Ra values were analyzed by two-way ANOVA followed by a Tukey HSD test $(\alpha=05)$.

Additional 8 ceramic specimens were prepared and glazed. The 6 specimens were roughened with a medium-grit diamond rotary cutting instrument and polished with 3 polishing systems, as previously described. Therefore, these specimens were $\mathrm{Au} / \mathrm{Pd}$ sputtered with a sputter coater (Polaron SC500 Sputter Coater, VG Microtech, E. Sussex, England) and examined under field emission SEM (LEO 440, Electron Microscopy Ltd, Cambridge, $\mathrm{UK})$ at $20 \mathrm{kV}$. The SEM photomicrographs were made with $\times 500$ magnification.

\section{Results}

The mean and standart deviations of surface roughness values $(\mu \mathrm{m})$ for Empress 2, Ceramco 3 porcelains were shown in Figure 1. The ANOVA indicated that there was relationship between the porcelain systems and polishing techniques but no significant differences between porcelain systems themselves for Ra values; $(p>0.05)$ (Table 2). The different polishing techniques affected surface roughness significantly $(p<0.01)$. Tukey HSD test showed that there were significant differences between the control groups (EC and FC) and polishing groups (EK, ES, EM, FK, FS, FM). Group FS was significantly different from all groups. Porcelain polishing systems produced significantly rougher surfaces than the glazed porcelains $(\mathrm{p}<0.01)$.

$\Delta \mathrm{E}$ values showed that there was a relationship between the porcelain systems and polishing techniques but no significant differences between porcelain systems ( $\mathrm{p}>$ 0.05) (Table 3). The different polishing techniques affected color differences significantly $(p<0.01)$. FS (Feldspathic ceramic-Oclusal brush set) was the most coloring material (Figure 2).

Results of the SEM examination indicated that the glazed ceramic specimens appeared to have a smoother surface (Figures 3 and 4). The polishing surfaces contained many pitted areas with numerous surface irregularities. Porcelain surfaces which were polished with silicon occlusal brushes contained more numerous surface irregularities (Figure 3(ES) and Figure 4(FS). The Meisinger ceramic polishing system appeared to have a smoother surface in the experimental groups (Figure 3(EM) and Figure 4(FM).

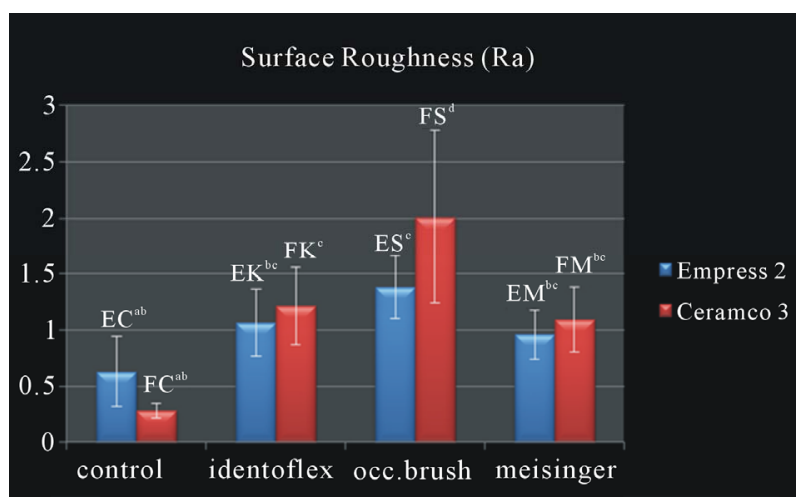

Figure 1. The mean Ra values between control and experimental groups. Same lowercase letters' group that were not statistically different $(p>0.05)$.

Table 2. Two-way ANOVA results for comparison of surface roughness $(\mu \mathrm{m})$.

\begin{tabular}{cccccc}
\hline Source & SS & DF & MS & F & $P$ \\
\hline Porcelain & 0.4 & 1 & 0.4 & 2.9 & 0.1 \\
Polishing & 15.48 & 3 & 5.16 & 37.4 & 0.00 \\
$\begin{array}{c}\text { Porcelain* } \\
\text { Polishing }\end{array}$ & 2.38 & 3 & 0.8 & 5.75 & 0.01 \\
\hline
\end{tabular}

Table 3. Two-way ANOVA results for comparison of $\Delta \mathbf{E}$ values.

\begin{tabular}{cccccc}
\hline Source & SS & DF & MS & F & $P$ \\
\hline Porcelain & 13.56 & 1 & 13.56 & 1.26 & 0.27 \\
Polishing & 502.29 & 2 & 251.14 & 23.31 & 0.00 \\
$\begin{array}{c}\text { Porcelain } \\
\text { Polishing }\end{array}$ & 57.06 & 2 & 28.53 & 2.65 & 0.08 \\
\hline
\end{tabular}




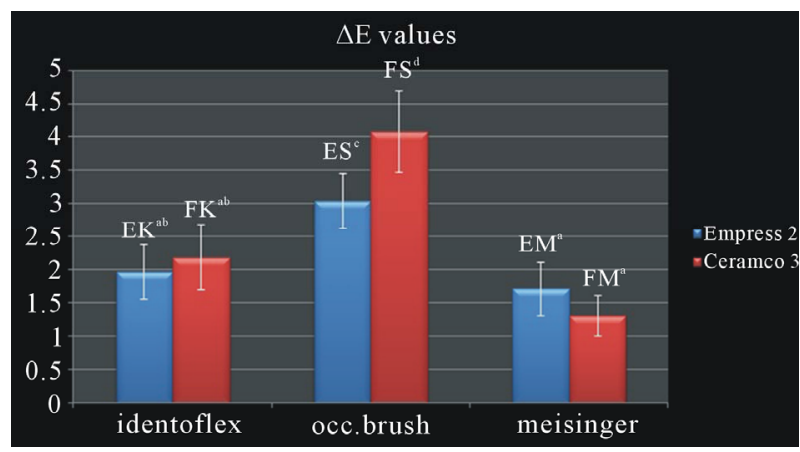

Figure 2. The mean $\Delta \mathbf{E}$ values of polishing groups. Same lowercase letters' group that were not statistically different $(\mathbf{p}>\mathbf{0 . 0 5})$.

\section{Discussion}

This study hypothesized that different porcelain polishing techniques and glazed surfaces would have similar smooth surface and color stabilty on specimens for feldspathic and lithium disilicate glass-ceramic systems.
However the research hypothesis was not corroborated by the results because significant differences were found in $\Delta \mathrm{E}$ and $\mathrm{Ra}$ values among the groups. Glazed porcelains had the smoothest surface among the groups. The silicon occlusal brush group had more irregular surface than other groups. On the other hand there was no significant difference between porcelain groups $(p>0.05)$.

Rough surfaces on the restorations increased plaque accumulation and abrasive wear of the opposing dentition [20,21]. Moreover, effective polishing prevented discoloration of rough surfaces. Irregular porcelain surfaces may concentrate stresses and begin cracking propagation resulting in premature fracture of the porcelain [22]. To increase the long term success of the restoration, the roughed surface must be smoothed by the polishing materials or glazing.

According to studies various finishing and polishing materials can be used to obtain a clinically acceptable smoothness of surfaces compared with glazing [23]. Nonetheless, other studies have shown that polished sur-
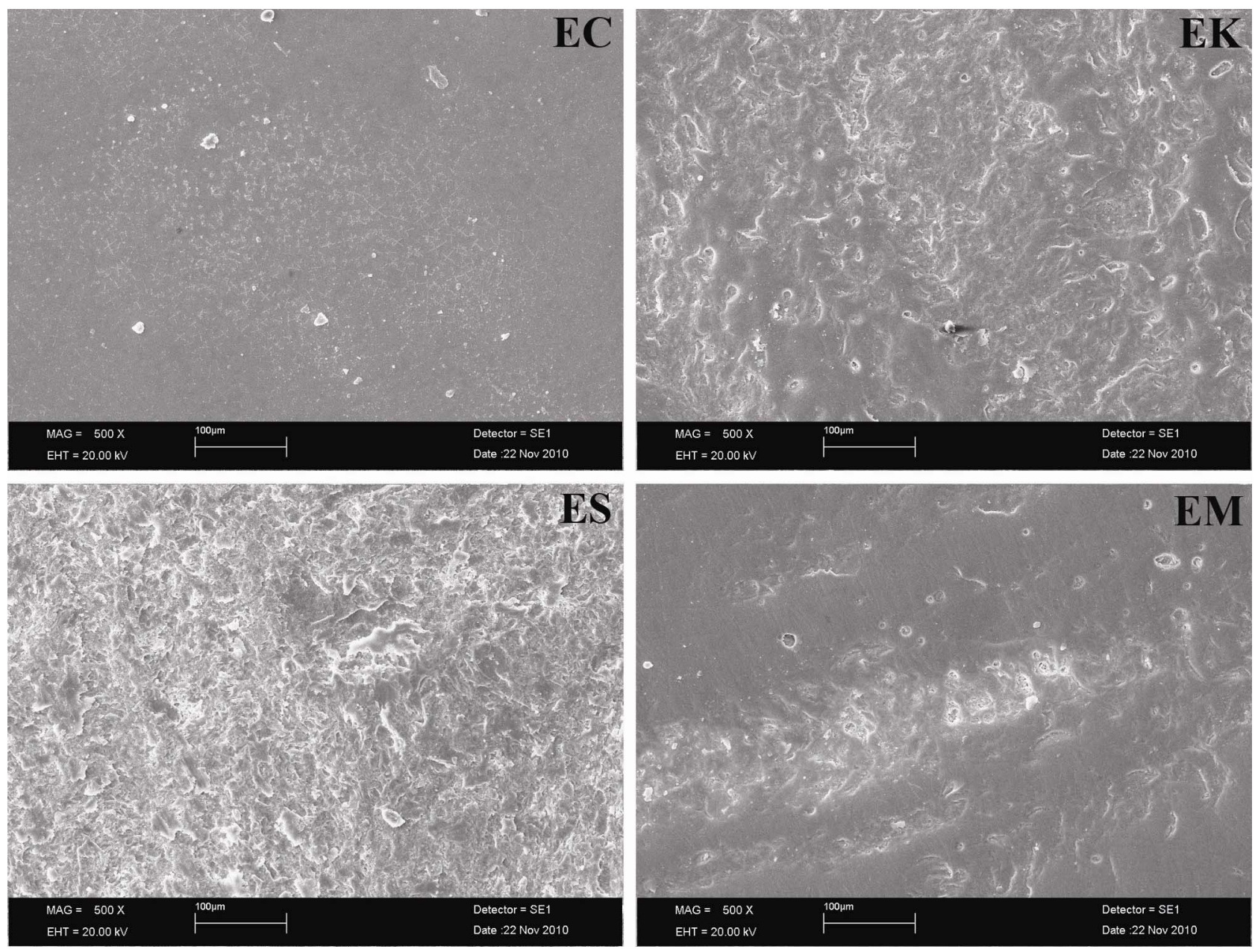

Figure 3. SEM micrographs of glazed and polished IPS Empress 2 surfaces $(\times 500$ magnification). EC: Glazed surface (control); EK: Polished with ceramic polisher (Identoflex); ES: Polished with occlusal brush set (Stoddard); EM: Polished with ceramic polisher (Meisinger). 

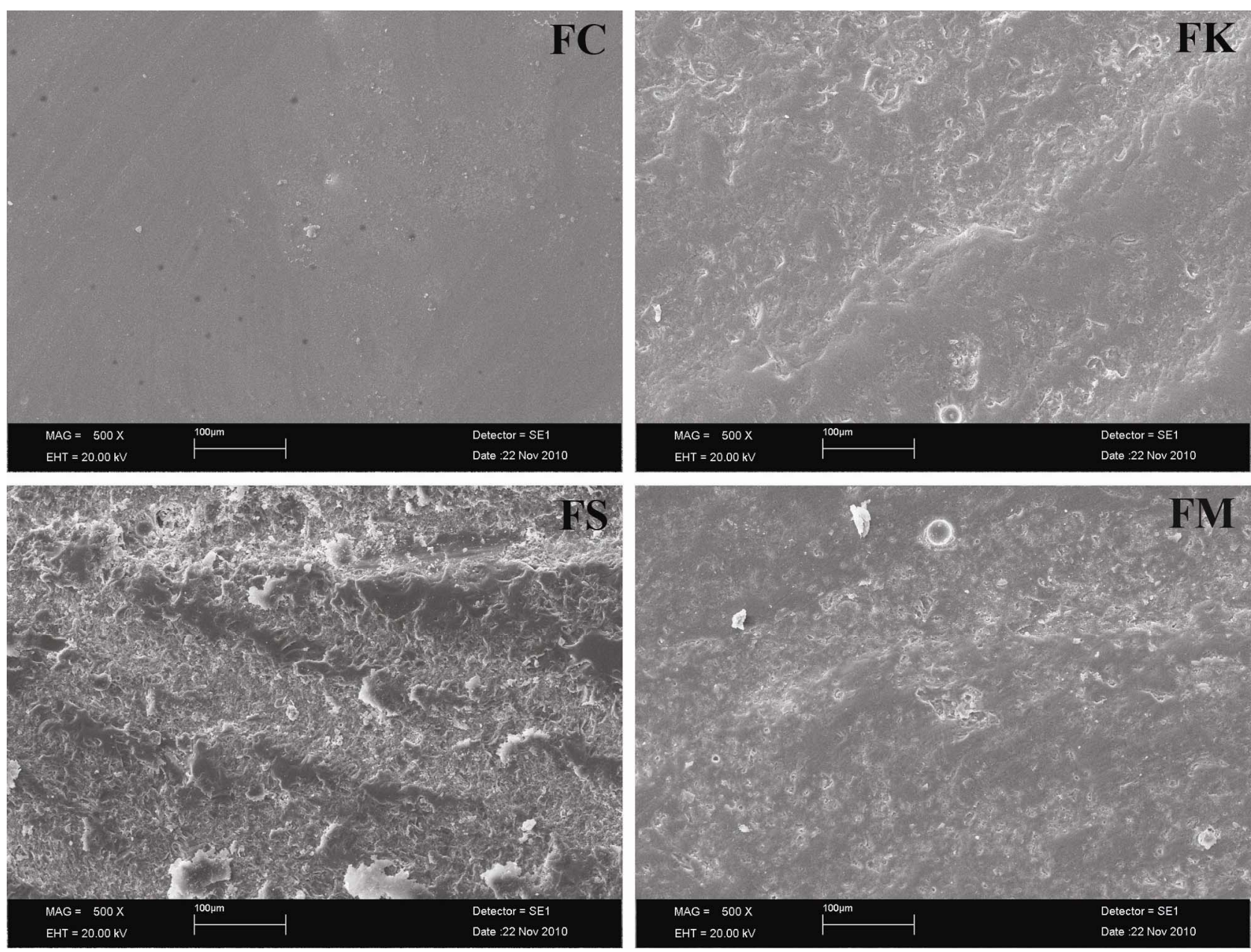

Figure 4. SEM micrographs of glazed and polished Ceramco 3 surfaces (x500 magnification). EC: Glazed surface (control); EK: Polished with ceramic polisher (Identoflex); ES: Polished with occlusal brush set (Stoddard); EM: Polished with ceramic polisher (Meisinger).

faces were rougher than glazed surfaces [24].

Alkhiary et al. [25] indicated that polishing of the ultra-low porcelain improved surface residual stresses. Rosenstiel et al. [26] also indicated that the fracture toughness of porcelain was greater than that of glazed porcelain. According to the author, this finding demonstrates that polishing procedure not only improves the surface roughness of ultra-low porcelain but also may improve porcelain's physical properties.

A study report that mechanical polishing was unable to reestablish sufficient surface polishing in compared to glazed surfaces for alumina reinforced feldspar ceramic [27].

Klauser et al. report that the shofu polishing kit was capable of produducing as smooth a surface as glazed porcelain [4].

Quantitative analysis by surface roughness was accompanied by qualitative analysis by SEM for this study. The profilometer and SEM verified that the smoothest porcelain surfaces were obtained after glazing. Among the polishing sets, the ceramic polishing system had the smoothest and the least staining surface. Taking account of typical wear patterns and allowing savings of diamond grit with this technology the twin zone tecnology of this system may be the source of this finding.

The higher $\Delta \mathrm{E}$ values and surface roughness were obtained with the use of occlusal brush. The ceramic polishing system consists of brushes and rubbers. All of them were used without water according to manufacturer instructions, the brushes stained the porcelain in the length of the time. Because porcelain is very hard material so it may be more useful for composites. Rubbers are more succesfull than brushes for polishing to porcelains.

Based on the result of this study, it may be suggested that roughened porcelain surfaces should be performed by glazing instead of polishing.

Sarac et al. [28] compared the effect of different porcelain polishing methods on the color and surface texture of the feldspathic porcelain and they found significant differences between the polishing techniques and color 
difference. $\Delta \mathrm{E}$ values ranged from 1.03 to 3.36 .The use of glaze material decreased the surface roughness and color change significantly.

Another study reported that the color differences between glazed and polished ceramic surfaces were compared using spectrophotometer. The grit size of the silicon carbide paper affected the color differences [29].

According to this study, $\Delta \mathrm{E}$ values were below the 3.7 $(\Delta \mathrm{E}<3.7)$ except FS, which can not be easily percieved by the human eye [7]. The polishing techniques affected the color differences significantly. $\Delta \mathrm{E}$ values showed that the color differences were at acceptable levels except FS $(\Delta \mathrm{E}=4)$.

\section{Conclusion}

Within the limitation of this study, it may be concluded that polishing procedures were not able to provide a porcelain surface as smooth as the glazed surface for the tested IPS empress II and Ceramco 3 porcelains. Rubber polishing systems are more succesful than brushes for polishing porcelains. Among the polishing techniques, glazing was more succesful than mechanical polishing (rubbers, brushes) for the surface color change of the porcelains. There was a positive correlation between the surface roughness and color differences. There was no statistically significant differences for surface roughness and color change between feldspathic and lithium disilicate glass-ceramic porcelains.

\section{Acknowledgements}

This study was supported by the Mustafa Kemal University Scientific Research Section.

\section{REFERENCES}

[1] K. J. Anusavice, "Phillip's Science of Dental Materials," 10th Edition, WB Saunders Company, Philadelphia, 1996.

[2] A. U. Yap, S. H. Yap, C. K. Teo and J. J. Ng, "Finishing/Polishing of Composite and Compomer Restoratives: Effectiveness of One-Step Systems," Oper Dent, Vol. 29, No. 3, 2004, pp. 275-279.

[3] A. Wahadni and D. M. Martin, "Glazing and Finishing Dental Porcelain: A Literature Review," Journal of the Canadian Dental Association, Vol. 64, No. 8, 1998, pp. 580-583.

[4] R. E. Goldstein, "Finishing of Composites and Laminates," Dental Clinics of North America, Vol. 33, No. 2, 1989, pp. 305-318.

[5] A. Vichi, C. Louca, G. Corciolani and M. Ferrari, "Color Related to Ceramic and Zirconia Restorations: A Review," Dental Materials, Vol. 27, No. 1, 2011, pp. 97-108. doi:10.1016/j.dental.2010.10.018

[6] G Knispel, "Factors Affecting the Process of Color Matching Restorative Materials to Natural Teeth," Quin- tessence International, Vol. 22, No. 7, 1991, pp. 525-531.

[7] R. R. Seghi, E. R. Hewlett and J. Kim, "Visual and Instrumental Colorimetric Assesments of Small Color Differences on Translucent Dental Porcelain," Journal of Dental Research, Vol. 68, No. 12, 1989, pp. 1760-1764. doi:10.1177/00220345890680120801

[8] R. L. Raimondo, J. T. Richardson and B. Wiedner, "Polished versus Autoglazed Dental Porcelain," Journal of Dental Research, Vol. 64, No. 5, 1990, pp. 553-557. doi:10.1016/0022-3913(90)90126-W

[9] K. J. Anusavice and R. W. Phillips, "Phillip's Science of Dental Materials," 11th Edition, Elsevier, St. Louis, 2003.

[10] C. J. Patterson, A. C. McLundie and D. R. Stirrups, "Efficacy of a Porcelain Refinishing System in Restoring Surface Finish after Grinding with Fine and Extra-Fine Diamonds Burs," Journal of Prosthetic Dentistry, Vol. 68, No. 3, 1992, pp. 402-406. doi:10.1016/0022-3913(92)90400-5

[11] W. D. Sulik and E. J. Plekavich, "Surface Finishing of Dental Porcelain," Journal of Prosthetic Dentistry, Vol. 46, No. 2, 1981, pp. 217-221. doi:10.1016/0022-3913(81)90312-7

[12] V. B. Haywood, H. O. Heymann, R. P. Kusy, J. Q. Whitley and S. B. Andreaus, "Polishing Porcelain Veneers: An SEM and Specular Reflectance Analysis," Dental Materials, Vol. 4, No. 3, 1988, pp. 116-121. doi:10.1016/S0109-5641(88)80003-4

[13] L. H. Klausner, C. B. Cartwright and G. T. Charbeneau, "Polished versus Autoglazed Porcelain Surfaces," Journal of Prosthetic Dentistry, Vol. 47, No. 2, 1982, pp. 157-162. doi:10.1016/0022-3913(82)90180-9

[14] A. O. E. El-Karaksi, G. I. Shehab and M. E. Eskander, "Effect of Reglazing and of Polishing on the Surface Roughness of New Ceramic Restoration (Hi Ceram)," Egyptian Dental Journal, Vol. 39, No. 3, 1993, pp. 485490.

[15] N. Barghi, C. J. King and R. A. Draughn, "A Study of Porcelain Surfaces as Utilized in Fixed Prosthodontics," Journal of Prosthetic Dentistry, Vol. 34, No. 3, 1975, pp. 314-319. doi:10.1016/0022-3913(75)90109-2

[16] R. S. Nishioka, M. A. Bottino and A. Trevisan, "Scanning Electron Microscopy Evaluations of Glazed Porcelain Surface and Intra-Oral Polishing Tecnique," Pós-Grad Rev Fac Odontol São José Campos, Vol. 2, No. 2, 1999, pp. 48-51.

[17] S. D. Campbell, "Evaluation of Surface Roughness and Polishing Techniques for New Ceramic Materials," Journal of Prosthetic Dentistry, Vol. 61, No. 5, 1989, pp. 563568. doi:10.1016/0022-3913(89)90276-X

[18] Y. Hosoya, "Five-Year Colour Changes of Light-Cured Resin Composites: Influence of Light Curing Times," Dental Materials, Vol. 15, No. 4, 1999, pp. 268-274. doi:10.1016/S0109-5641(99)00046-9

[19] G. Heydecke, F. Zhang and E. Razzoog, "In Vitro Color Stability of Double Layer Veneers after Accelerated Aging," Journal of Prosthetic Dentistry, Vol. 85, No. 6, 2001, pp. 551-557. doi:10.1067/mpr.2001.115385

[20] D. C. Jagger and A. Harrison, "An in Vitro Investigation 
into the Wear Effects of Unglazed, Glazed, and Polished Porcelain on Human Enamel," Journal of Prosthetic Dentistry, Vol. 72, No. 3, 1994, pp. 320-323.

doi:10.1016/0022-3913(94)90347-6

[21] E. R. Schlissel, D. A. Newitter, R. R. Renner and A. J. Gwinnett, "An Evaluation of Post Adjustment Polishing Techniques for Porcelain Denture Teeth," Journal of Prosthetic Dentistry, Vol. 43, No. 3, 1980, pp. 258-265. doi:10.1016/0022-3913(80)90399-6

[22] H. Fisher, M. Schafer and R. Marcs, "Effects of Surface Roughness on Flexural Strength of Veneer Ceramics," Journal of Prosthetic Dentistry, Vol. 82, No. 12, 2003, pp. 972-975. doi:10.1177/154405910308201207

[23] U. Lohbauer, F. A. Muller and A. Petschelt, "Influence of Surface Roughness on Mechanical Strength of Resin Composite versus Glass Ceramic Materials," Dental Materials, Vol. 24, No. 2, 2008, pp. 250-256. doi:10.1016/j.dental.2007.05.006

[24] N. Barghi, C. J. King and R. A. Draughn, "A Study of porcelain Surfaces as Utilized in Fixed Prosthodontics," Journal of Prosthetic Dentistry, Vol. 34, No. 3, 1975, pp. 314-319.
[25] C. J. Patterson, A. C. McLundie, D. R. Stirrups and W. G. Taylor, "Refinishing of Porcelain by Using a Refinishing Kit," Journal of Prosthetic Dentistry, Vol. 65, No. 3, 1991, pp. 383-388. doi:10.1016/0022-3913(91)90229-P

[26] S. F. Rosenstiel, M. A. Baiker and W. M. Johnston, "A Comparison of Glazed and Polished Dental Porcelain," International Journal of Prosthodontics, Vol. 2, No. 6, 1989, pp. 524-529.

[27] M. C. Bottino, L. F. Valandro, K. Z. Kantorsk1, J. C. Bressianı and M. A. Bottino, "Polishing Methods of an Alumina-Reinforced Feldspar Ceramic," Brazilian Dental Journal, Vol. 17, No. 4, 2006, pp. 285-289. doi:10.1590/S0103-64402006000400004

[28] D. Sarac, Y. S. Sarac, S. Kulunk, C. Ural and T. Kulunk, "The Effect of Polishing Techniques on the Surface Roughness and Color Change of Composite Resins," Journal of Prosthetic Dentistry, Vol. 96, No. 1, 2006, pp. 3340. doi:10.1016/j.prosdent.2006.04.012

[29] A. U. Yap, "Color Attributes and Accuracy of Vita-Based Manufacturer's Shade Guides," Operative Dentistry, Vol. 23, No. 5, 1998, pp. 266-267. 